\title{
Adult binge drinking: rate, frequency and intensity in Buffalo City Metropolitan Municipality, South Africa
}

\author{
Eyitayo Omolara Owolabia*, Daniel Ter Goona, Oladele Vincent Adeniyi ${ }^{\mathrm{b}}$ (D) and Eunice Seekoe ${ }^{\mathrm{a}}$ \\ ${ }^{a}$ Department of Nursing Science, University of Fort Hare, East London, South Africa \\ ${ }^{b}$ Department of Family Medicine, Walter Sisulu University/Cecilia Makiwane Hospital, East London, South Africa \\ ${ }^{*}$ Corresponding author, email: owolabiomolara101@gmail.com
}

Background: Binge drinking (BD) is a significant risk factor for several acute and chronic illnesses, including injuries. This study examines the rate, frequency and intensity of BD in Buffalo City Metropolitan Municipality (BCMM), South Africa.

Methods: This was a cross-sectional survey of 998 adults attending the three largest outpatient clinics in BCMM. Rate, frequency and intensity of BD were assessed using the WHO STEPwise questionnaire. Descriptive and inferential statistics were carried out to determine the rate and determinants of binge drinking.

Results: The overall rate of BD was $15.0 \%$. Frequency and intensity of BD were 5.4 episodes per month and 13.4 drinks on one occasion, respectively. The study data showed that BD was commoner in males than females ( $24.0 \%$ vs. $10.8 \%)$. Smokers engage more in BD than non-smokers (44.0\% vs. 9.9\%). In the analysis of socio-demographic variables, BD was commonest among students, age group 18-25 years, those never married and those on incomes between 2001 and 5000 Rand per month. In the multivariate logistic regression, after adjusting for confounders, only age less than 25 years $(p<0.001)$ and male gender ( $p<$ $0.001)$ were significant predictors of binge drinking. Also, male gender $(p=0.002)$ was significantly associated with frequency of $\mathrm{BD}$. There was no significant gender variation in the intensity of BD. Only age and smoking were significantly associated with the intensity of BD.

Conclusion: The rate of binge drinking was high among the study participants, and those who binge drink tend to do so frequently and at a high intensity. Women who binge drink also do so at a high intensity. There is a need for sensitisation campaigns and health advocacy talks on the dangers associated with binge drinking among young adults in this setting.

Keywords: Binge drinking, Buffalo City, frequency, intensity, rate, South Africa

\section{Introduction}

Alcohol is a mind-altering substance that has been in use for centuries and in various cultures and it is associated with varieties of health, social and economic burden. ${ }^{1}$ Globally, alcohol use is the third leading modifiable risk factor for morbidity and mortality and the first leading risk factor in middle-income countries. ${ }^{2}$ Alcohol use is responsible for 3.3 million deaths (5.9\%) worldwide and a cause of over 200 diseases and injuries. ${ }^{3}$

Alcohol is a leading risk factor for morbidity and mortality in South Africa. ${ }^{4}$ South Africa is considered a hard-drinking country with an annual per-capita consumption rate of 5 billion litres, one of the highest recorded globally.3,5 Excessive alcohol consumption constitutes a significant public health threat for South Africans. ${ }^{5,7}$ Alcohol use in South Africa is often characterised by abstinence from alcohol juxtaposed with heavy episodic drinking, basically binge drinking, with a significant rise among females and a relatively stable rate among males. ${ }^{7}$ Alcohol use in South Africa varies by gender, race and province. ${ }^{8}$

Binge drinking, defined as the consumption of four or more alcoholic drinks among women or five or more among men on a single occasion, is a form of hazardous drinking. ${ }^{7,9}$ Binge drinking often results in acute impairment with numerous health consequences and constitutes a risk factor for several chronic and acute traumas and illnesses such as motor vehicle accidents, violence, suicide, hypertension, acute myocardial infarction, and sexually transmitted diseases among others.,10 Binge drinking increases the risks of breast cancer and unintended pregnancies in women in the reproductive age group, sudden infant death and foetal alcohol spectrum disorders during pregnancy. ${ }^{9}$

Apart from the prevalence of binge drinking, the frequency and intensity of binge drinking are two other important measures for determining the adverse health outcomes of hazardous alcohol use. ${ }^{11}$ The frequency of binge drinking is defined as the number of binge-drinking episodes over a certain time period while intensity is defined as the average number of drinks consumed per episode of binge drinking. ${ }^{12}$ These two measures, frequency and intensity, have been reported to contribute significantly to poor healthrelated quality of life as well as alcohol-related morbidity and mortality. ${ }^{11,13}$ Several studies have reported the prevalence of alcohol use in South Africa. ${ }^{5,7,8,14}$ However, binge drinking has rarely been investigated in the Eastern Cape Province, an economically disadvantaged province with an anecdotal report of high alcohol-drinking habits. Most importantly, no study has been conducted in South Africa on the frequency and intensity of binge drinking among individuals who binge drink. Such information is vital in determining the severity and pattern of binge drinking, and assessing the population at risk of adverse health outcomes of alcohol use, as well as crafting effective public health policies targeted towards the reduction of harmful alcohol 
use. This study aimed at determining the rate, frequency and intensity of binge drinking among adults in BCMM, South Africa.

\section{Study methods \\ Study settings and participants}

This cross-sectional study forms part of the Buffalo City Metropolitan Municipality (BCMM) Non-Communicable Disease Surveillance Study. The methods for the larger study have been published elsewhere. ${ }^{15}$ Briefly, participants were recruited from the three largest outpatient clinics: Cecilia Makiwane hospital, and Nontyatyambo and Empilweni-Gompo Community Health Centres. These health facilities are located in the rural and semiurban communities of $\mathrm{BCMM}$ and provide healthcare services for a total of 755200 residents in BCMM. ${ }^{16}$ Buffalo City Metropolitan Municipality is situated on the east coast of Eastern Cape Province and consists of the towns of East London, King William's Town, Bisho and the large townships of Mdantsane and Zwelitsha. The majority (85.1\%) of the residents of BCMM are black Africans, with $6.0 \%$ coloured population, 0.8\% Asian/ Indians and $7.7 \%$ whites. ${ }^{16}$

\section{Sample and sampling technique}

The appropriate sample size was estimated using the following formula:

$N=\left(Z_{1-\alpha}\right)^{2} \times(P(1-p)) / D^{2}$

Where $Z_{1-\alpha}$ is the confidence level, $P$ is the expected proportion of individuals with cardio-metabolic risk factors, and $D$ is the margin of error. $P$ was set at 0.40 and $D$ at 0.05 . The calculation was performed at $95 \%$ confidence level. The required sample size (1 107 participants; 369 per study site) was included in the study. All ambulatory individuals (both patients and relatives) who fulfilled the inclusion criteria and were available during the period of study were conveniently recruited. The study was conducted in April and May 2016. Participants were included if they were 18 years and above. However, debilitated, pregnant, breastfeeding or individuals with psychiatric disorders were excluded from the study. Due to incomplete data, 199 participants were excluded, thus a total of 998 participants were included in the data analysis.

\section{Data collection}

\section{Study instrument}

The previously validated WHO STEPwise questionnaire ${ }^{17}$ was used to obtain information from the study participants. It comprised three major items: demographic and behavioural data, and measurements. The instrument was adapted locally and a pilot study that included 20 participants at one of the sites was conducted to validate its suitability in the local setting as well as to test the effectiveness of the research process. However, the result of the pilot study was not included in the analysis.

\section{Study procedure}

Data were obtained by personal interview on demographic and behavioural characteristics using the WHO STEPwise questionnaire. Demographic variables included items on sex, age, marital status, level of education, employment status and average monthly income. Participants' income was categorised into R2000 or less per month, R2001-5000 and above R5000. Their level of education was determined by self-reporting of the highest grade level attained in school and was categorised as having no formal education, primary (grade 1-7), secondary (grade 8-12) or tertiary (post-secondary). Participants were defined as unemployed if they reported that they were not employed in either the formal or informal sector.

Binge drinking was defined as self-reported consumption of four or more standard alcoholic drinks on one occasion by women or five or more standard alcoholic drinks on one occasion by men in the past 30 days. Frequency of binge drinking was defined as the average number of episodes of binge drinking while intensity of binge drinking was defined as the average number of drinks consumed during occasions of binge drinking in the past 30 days.

\section{Data analysis}

Descriptive and inferential statistics were used for the data analysis. Frequencies $(n)$ and proportions (\%) were reported for categorical variables. The associations between the demographic variables and binge drinking were assessed through bivariate analysis. Multivariate analysis was used to ascertain the determinants of binge drinking. Mean frequency and intensity were compared across the socio-demographic variables using analysis of variance (ANOVA). Analysis was carried out at a 95\% confidence level. A pvalue of $<0.05$ was considered statistically significant. The Statistical Package for Social Science (SPSS ${ }^{\circledR}$ ) version 21.0 was used for the data analysis (IBM Corp, Armonk, NY, USA).

\section{Ethical considerations}

Ethical approval was obtained from the University of Fort Hare Research Ethics Committee (Reference number,GOO061SOLO01). Afterwards, permission to conduct the study was obtained from the Eastern Cape Department of Health, the management of the Sub-District Department of Health in Buffalo City Metropolitan Municipality and finally the management of the respective health facilities. Participants received detailed information on the purpose and process of the study. Each participant subsequently gave written, informed consent for his/her voluntary participation in the study including referral to clinicians for interventions in the event of abnormal findings. The participants' right to privacy, confidentiality and anonymity were taken into consideration.

\section{Results}

Table 1 presents the demographic characteristics of the participants. A total of 998 participants were included in the analysis. The mean age of participants was 42.6 (SD \pm 16.5 ) years, with an age range of 18 to 75 years. The majority of the participants were black (98.1\%), female (67.8\%), single (63.9\%) and had at least a grade 8 level of education (69.7\%). About half of the participants had no means of income (44.6\%) and were unemployed (47.7\%), while only a few $(7.5 \%)$ participants earned above R5000 monthly.

Of the 998 participants, the prevalence of binge drinking was $15 \%$ ( $n=150)$. However, $47 \%$ of those who reported current alcohol consumption ( $n=319)$ binge drink.

As shown in Table 2, gender, age, marital status, employment status, income categories, body mass index (BMI) categories and smoking were statistically associated with binge drinking. Binge drinking was highest among males (24\%), participants aged 18 to 25 years $(24.6 \%)$, those never married $(19.2 \%)$, students $(23.2 \%)$, those earning an income of R2001 to R5000 per month (21.8\%), those who were underweight (21.9) and current smokers (44\%). 
Table 1: Demographic characteristics of the participants by gender

\begin{tabular}{|c|c|c|c|}
\hline Variables & $\begin{array}{c}\text { Male } \\
(n=321) n(\%)\end{array}$ & $\begin{array}{c}\text { Female } \\
(n=677) n(\%)\end{array}$ & $\begin{array}{c}\text { Total } \\
(n=998) n(\%)\end{array}$ \\
\hline \multicolumn{4}{|l|}{ Age group (years): } \\
\hline $18-25$ & $40(12.5)$ & $143(21.1)$ & $183(18.3)$ \\
\hline $26-35$ & $74(23.1)$ & $149(22.0)$ & $223(22.3)$ \\
\hline $36-45$ & $67(20.9)$ & $116(17.1)$ & $183(18.3)$ \\
\hline $46-55$ & $57(17.8)$ & $110(16.2)$ & $167(16.7)$ \\
\hline $56-65$ & $41(12.8)$ & 99 (14.6) & $140(14.0)$ \\
\hline$\geq 66$ & $42(14.1)$ & $60(8.9)$ & $102(10.2)$ \\
\hline \multicolumn{4}{|l|}{ Level of education: } \\
\hline $\begin{array}{l}\text { No formal } \\
\text { schooling }\end{array}$ & $62(19.3)$ & $84(12.4)$ & $146(14.6)$ \\
\hline Grade 1-7 & $57(17.8)$ & $99(14.6)$ & $156(15.6)$ \\
\hline Grade 8-12 & $171(53.3)$ & $409(60.4)$ & $580(58.1)$ \\
\hline Tertiary & $31(9.7)$ & 85 (12.6) & $116(11.6)$ \\
\hline \multicolumn{4}{|c|}{ Monthly income (Rand): } \\
\hline No income & $134(41.7)$ & $300(44.3)$ & $445(44.6)$ \\
\hline R150-2000 & $89(27.7)$ & $248(36.6)$ & $326(32.7)$ \\
\hline R2001-5000 & $74(23.1)$ & $100(14.8)$ & $174(17.4)$ \\
\hline R5001and above & $24(7.5)$ & $29(4.3$ & $53(5.3)$ \\
\hline \multicolumn{4}{|l|}{ Marital status: } \\
\hline Single & $193(60.3)$ & $444(65.6)$ & $637(63.9)$ \\
\hline Married & $115(35.9)$ & $185(27.3)$ & $300(30.1)$ \\
\hline Separated & $1(0.3)$ & $5(0.7)$ & $6(0.6)$ \\
\hline Divorced & $9(2.8)$ & $13(1.9)$ & $22(2.2)$ \\
\hline Widowed & $2(0.6)$ & $30(4.4)$ & $32(3.2)$ \\
\hline \multicolumn{4}{|l|}{ Racial group: } \\
\hline Black & $313(97.5)$ & $666(98.4)$ & $979(98.1)$ \\
\hline Coloured & $8(2.8)$ & $9(1.3)$ & $17(1.7)$ \\
\hline White & $0(0.0)$ & $2(0.3)$ & $2(0.2)$ \\
\hline \multicolumn{4}{|l|}{ Type of employment: } \\
\hline $\begin{array}{l}\text { Government } \\
\text { employee }\end{array}$ & $30(9.3)$ & $33(4.9)$ & $63(6.3)$ \\
\hline $\begin{array}{l}\text { Non-government } \\
\text { employment }\end{array}$ & $98(30.5)$ & $133(19.7)$ & $231(23.2)$ \\
\hline Self-employment & $30(9.3)$ & $32(4.7)$ & $62(6.2)$ \\
\hline Students & $19(5.9)$ & $80(11.8)$ & $99(9.9)$ \\
\hline Unemployed & $115(24.2)$ & $361(53.4)$ & $476(47.7)$ \\
\hline Retired & $29(9.0)$ & $37(5.5)$ & 66 (6.6) \\
\hline
\end{tabular}

In the multivariate regression, only age less than 25 years, male gender and current smoking were significant predictors of binge drinking. Participants aged less than 25 years were three times more likely to binge drink compared to those above 25 years. Males were twice as likely to binge drink compared to females while smokers were about seven times more likely to binge drink than non-smokers (Table 3).

The mean frequency of binge drinking was 5.4 episodes and it ranged from 1.0 to 32.0 episodes. Sex was the only significant factor associated with the frequency of binge drinking ( $p$ - value $=0.002)$. Male participants had a higher frequency of binge drinking (6.4 episodes) (Table 4).

The mean intensity of binge drinking among the study participants was 13.4 drinks (4.0-56.0 drinks) with no significant gender variation. Age and smoking were significantly associated with the intensity of binge drinking. The highest mean intensity of binge drinking was found among participants aged 36 to 45 years ( 16.0 drinks) and current smokers (13.9 drinks) (Table 5).

\section{Discussion}

Binge drinking is an essential public health issue that often results in acute impairment with several health consequences. ${ }^{3}$ Of the 998 participants, 15\% binge drink, while $47 \%$ of current alcohol users binge drink. The rate of binge drinking among adults in this setting in Eastern Cape Province is higher than the reported national prevalence of $9.7 \%{ }^{18}$ This points at the documented increase in hazardous alcohol use in South Africa. ${ }^{5}$ This rate is slightly lower than the reported prevalence among US adults, which ranged from $17.1 \%$ to $23 \%$ between 2010 and 2015. ${ }^{9,19,20}$ Harmful alcohol users are not only at risk, but also put others at risk. Considering its significant adverse health and social impacts, harmful alcohol use requires health intervention measures among the general population.

Binge drinking was found to be higher among males, younger participants (aged 18-25 years), never-married participants and students. This is not surprising, as several studies have documented similar findings..$^{9,19,21}$ Males have been reported as the most frequent perpetrators of harmful alcohol use. ${ }^{5,22,23}$ Alcohol use is perceived to be more socially acceptable among males than females and this might be the underlying factor for the higher rate recorded among the male participants. However, evidence indicates a convergence in the prevalence of alcohol use among the two genders, as the gap has been documented to be closing in recent years. ${ }^{7,24}$ The increase in hazardous drinking among women in this setting could be attributed to women's rights and social status. ${ }^{25}$ This trend portends grave danger in the region for increasing unintended pregnancies, sexually transmitted infections, especially HIV, and the risks of sudden infant deaths and foetal alcohol spectrum disorders during pregnancy. Thus, alcohol reduction interventions should not only target males; rather, both sexes should be targeted as there is a possibility of escalation of this burden in the near future.

Also, those in the younger age group binge drink more than the older participants. This corroborates the findings of Reddy et al. ${ }^{21}$ in a National Youth Survey in South Africa, which reported a high (25.1\%) prevalence of binge drinking. This might also explain the high prevalence found among students and single participants as they constitute the majority of the younger age group. Hazardous and binge drinking have been identified as habits commonly found among youths. These often decline with age, as people become mature, undertake more responsibilities or even develop health problems. ${ }^{26}$ Other reasons could be peer pressure, boredom, ignorance of the harmful effects of alcohol use, the relatively low price of alcohol, as well as ease of access to alcohol, evidenced by growing numbers of unlicensed liquor outlets in South Africa. ${ }^{5}$ Young adults should be specifically targeted for screening and interventions by primary health care physicians in the study setting. This is supported by evidence 
Table 2: Association between socio-demographic characteristics and binge drinking

\begin{tabular}{|c|c|c|c|}
\hline Variables & Binge drink & $\begin{array}{c}\text { Do not binge } \\
\text { drink }\end{array}$ & $p$-value \\
\hline \multicolumn{4}{|l|}{ Gender: } \\
\hline Male & $77(24.0)$ & $244(76.0)$ & $<0.001$ \\
\hline Female & $73(10.8)$ & $604(89.2)$ & \\
\hline \multicolumn{4}{|l|}{ Age (years): } \\
\hline $18-25$ & $45(24.6)$ & $138(75.4)$ & \\
\hline $26-35$ & $45(20.2)$ & $178(79.8)$ & \\
\hline $36-45$ & $24(13.1)$ & $159(86.9)$ & $<0.001$ \\
\hline $46-55$ & $25(15.0)$ & $142(85.0)$ & \\
\hline $56-65$ & $8(5.7)$ & $132(94.3)$ & \\
\hline$\geq 66$ & $3(15.0)$ & $99(85.0)$ & \\
\hline \multicolumn{4}{|l|}{ Level of education: } \\
\hline $\begin{array}{l}\text { No formal } \\
\text { schooling }\end{array}$ & $27(18.5)$ & $119(81.5)$ & \\
\hline Grade 1 to 7 & $14(9.0)$ & $142(91.0)$ & \\
\hline Grade 8 to 12 & $89(15.3)$ & $491(84.7)$ & 0.096 \\
\hline Tertiary & $20(17.2)$ & $96(82.8)$ & \\
\hline \multicolumn{4}{|l|}{ Marital status: } \\
\hline Never married & $122(19.2)$ & $515(80.8)$ & $<0.001$ \\
\hline Married & $28(7.8)$ & $332(92.2)$ & \\
\hline \multicolumn{4}{|c|}{ Employment status: } \\
\hline $\begin{array}{l}\text { Government } \\
\text { employee }\end{array}$ & $9(14.3)$ & $54(85.7)$ & \\
\hline $\begin{array}{l}\text { Non-govern- } \\
\text { ment employee }\end{array}$ & $47(20.3)$ & $184(79.7)$ & \\
\hline Self-employed & $9(14.5)$ & $53(85.5)$ & \\
\hline Student & $23(23.2)$ & $76(76.8)$ & 0.001 \\
\hline Unemployed & $60(12.6)$ & $416(87.4)$ & \\
\hline Retired & $2(3.0)$ & $64(97.0)$ & \\
\hline \multicolumn{4}{|c|}{ Income categories (Rand): } \\
\hline No income & $73(16.4)$ & $372(83.6)$ & \\
\hline $150-2000$ & $32(9.8)$ & $294(90.2)$ & \\
\hline $2001-5000$ & $38(21.8)$ & $136(78.2)$ & 0.003 \\
\hline Above 5000 & $7(13.2)$ & $46(86.8)$ & \\
\hline \multicolumn{4}{|c|}{ Body mass index categories: } \\
\hline Underweight & $9(25.0)$ & $27(75.0)$ & \\
\hline Normal & $55(20.3)$ & $216(79.7)$ & \\
\hline Overweight & $44(18.3)$ & $196(81.7)$ & $<0.001$ \\
\hline Obese & $42(9.3)$ & $409(90.7)$ & \\
\hline \multicolumn{4}{|l|}{ Current smoker: } \\
\hline Yes & $66(44.0)$ & $84(56.0)$ & $<0.001$ \\
\hline No & $84(9.9)$ & $764(90.1)$ & \\
\hline
\end{tabular}

$\mathrm{OR}=$ odds ratio; $\mathrm{Cl}=$ confidence interval.

and recommendation of the United States Preventive Services Task Force ${ }^{27}$ on screening of patients 18 years or older for alcohol misuse during consultation by primary care physicians, thus creating opportunity for behavioural counselling interventions.
Binge drinking was also found to be higher among those participants earning between R2000 and R5000. This finding is similar to those of Keyes and Hasin, ${ }^{28}$ Cerdá et al. ${ }^{29}$ Matheson et al., ${ }^{30}$ Mulia and Karriker-Jaffe ${ }^{31}$ and Public Health England..$^{32}$ The high prevalence of binge drinking found among low-income earners has been associated with poverty-inflicted economic deprivation and stress experienced by low-income earners. As such, alcohol use is seen as an 'easy way' out with a tendency to drink at a hazardous rate. ${ }^{31,33,34}$ Also, nutritional deficiency has been documented as one of the adverse effects of binge drinking, ${ }^{35}$ thus supporting the observed higher rate found among underweight patients.

Binge drinking was found to be higher among smokers. Smoking and harmful alcohol use often goes hand-in-hand..$^{36}$ Thus, the higher rate of binge drinking found among cigarette smokers is not surprising. ${ }^{37,38}$ The relationship between smoking and alcohol has long been documented. ${ }^{37-39}$ Alcohol use and smoking have been reported to be complementary behaviours. ${ }^{39}$ Several factors have been identified to be closely associated with this. Such factors range from physiological to psychological factors. Repeated use of nicotine, the major component of cigarettes, has been implicated in stimulating alcohol consumption. ${ }^{40}$ Also, nicotine has been shown to reduce the intoxicating effects of alcohol, which could prompt individuals seeking the intoxicating effect to drink more. ${ }^{22,41}$ Since both behaviours are complementary and the major focus of primary health physicians is often on smoking, there is an urgent need to integrate screening and behavioural counselling interventions for both lifestyle habits at the primary health care facilities in the region. Likewise, prevention programmes should take cognisance of both behaviours, and there should be a reconsideration of the long-separated public health policies relating to tobacco and alcohol use.

The mean frequency of binge drinking among the study participants was 5.4 episodes (1.0-32.0 episodes) with a significant gender difference. However, the mean intensity of binge drinking was 13.4 drinks (4.0-56.0 drinks) with no significant gender difference. To the best knowledge of the authors, no study in South Africa has been conducted on the frequency and intensity of binge drinking among binge drinkers.

Table 3: Multivariate logistic regression showing predictors of binge drinking

\begin{tabular}{|c|c|c|c|c|}
\hline Variables & $\beta$ & Wald & $\begin{array}{c}\text { Adjusted odds } \\
\text { ratio }(95 \% \mathrm{Cl})\end{array}$ & $p$-value \\
\hline \multicolumn{5}{|l|}{ Age (years): } \\
\hline$\leq 25$ & 1.2 & 12.4 & $3.4(1.7-6.8)$ & $<0.001$ \\
\hline \multicolumn{5}{|l|}{$\begin{array}{l}25 \text { and above } \\
\text { (reference) }\end{array}$} \\
\hline \multicolumn{5}{|l|}{ Gender: } \\
\hline Male & 0.8 & 7.5 & $2.3(1.3-4.1)$ & 0.006 \\
\hline \multicolumn{5}{|l|}{ Female (reference) } \\
\hline \multicolumn{5}{|l|}{ Smoking: } \\
\hline Yes & 1.9 & 37.8 & $6.5(3.5-11.9)$ & $<0.001$ \\
\hline \multicolumn{5}{|l|}{ No (reference) } \\
\hline \multicolumn{5}{|l|}{ Income (Rand): } \\
\hline Less than 3000 & 0.4 & 2.2 & $1.5(0.9-2.7)$ & 0.136 \\
\hline $\begin{array}{l}3000 \text { and above } \\
\text { (reference) }\end{array}$ & & & & \\
\hline
\end{tabular}


Table 4: Distribution of mean frequency of binge drinking by sociodemographic variables using ANOVA

\begin{tabular}{|c|c|c|c|c|}
\hline Variables & $n$ & Mean & SD & $p$-value \\
\hline \multicolumn{5}{|l|}{ Age (years): } \\
\hline $18-25$ & 45 & 4.8 & 4.5 & \\
\hline $26-35$ & 45 & 5.6 & 4.9 & \\
\hline $36-45$ & 24 & 6.8 & 2.5 & \\
\hline $46-55$ & 25 & 4.6 & 4.0 & 0.393 \\
\hline $56-65$ & 8 & 6.2 & 2.9 & \\
\hline Above 65 & 3 & 4.7 & 0.6 & \\
\hline \multicolumn{5}{|l|}{ Sex: } \\
\hline Male & 77 & 6.4 & 5.2 & 0.002 \\
\hline Female & 73 & 4.3 & 2.4 & \\
\hline \multicolumn{5}{|l|}{ Level of education: } \\
\hline No formal schooling & 27 & 4.6 & 1.2 & \\
\hline Grade 1-7 & 14 & 5.5 & 3.6 & \\
\hline Grade 8-12 & 89 & 5.9 & 4.9 & 0.226 \\
\hline Tertiary & 20 & 4.0 & 3.0 & \\
\hline \multicolumn{5}{|l|}{ Marital status: } \\
\hline Never married & 122 & 5.4 & 4.3 & 0.893 \\
\hline Ever married & 27 & 5.5 & 4.0 & \\
\hline \multicolumn{5}{|l|}{ Smoker: } \\
\hline Yes & 66 & 5.9 & 4.7 & 0.154 \\
\hline No & 84 & 4.9 & 3.7 & \\
\hline \multicolumn{5}{|c|}{ Income categories (Rand): } \\
\hline No income & 73 & 5.3 & 5.3 & \\
\hline $150-2000$ & 32 & 4.9 & 2.7 & \\
\hline $2001-5000$ & 38 & 5.5 & 3.0 & 0.658 \\
\hline Above 5000 & 7 & 7.1 & 2.6 & \\
\hline \multicolumn{5}{|l|}{ Employment status: } \\
\hline Government & 9 & 6.1 & 2.5 & \\
\hline Non-government & 47 & 5.7 & 2.7 & \\
\hline Self-employed & 9 & 7.8 & 9.7 & 0.427 \\
\hline Student & 23 & 4.9 & 4.3 & \\
\hline Unemployed & 60 & 4.8 & 4.0 & \\
\hline Retired & 3 & 6.5 & 2.1 & \\
\hline
\end{tabular}

As such, the finding concerning the frequency and intensity of binge drinking in our sample could only be compared with studies elsewhere. The frequency and intensity of binge drinking in this present study is higher than the reported frequency and intensity among US adults, with 4.1 episodes and 7.7 drinks, respectively. ${ }^{9}$ This finding substantiates the documented hazardous pattern of drinking reported among South Africans. ${ }^{7}$ Considering the detrimental effect of high frequency and intensity of binge drinking on health-related quality of life, there is a need to intensify efforts to reduce this unhealthy lifestyle behaviour among adults in Buffalo City Metropole. Health education of patients attending healthcare facilities on these harmful behaviours should also be prioritised in the district.

Additionally, male participants had a higher frequency of binge drinking. Harmful alcohol use has been reported to be higher among this group ${ }^{23}$ and, as such, the higher frequency of binge drinking found among them is not surprising. However, no
Table 5: Distribution of mean intensity of binge drinking across sociodemographic variables using ANOVA

\begin{tabular}{|c|c|c|c|c|}
\hline Variable & $n$ & Mean & SD & $p$-value \\
\hline \multicolumn{5}{|l|}{ Age (years): } \\
\hline $18-25$ & 45 & 11.9 & 7.7 & \\
\hline $26-35$ & 45 & 15.7 & 12.5 & \\
\hline $36-45$ & 24 & 16.0 & 9.2 & 0.042 \\
\hline $46-55$ & 25 & 10.0 & 6.0 & \\
\hline $56-65$ & 8 & 15.8 & 8.2 & \\
\hline Above 65 & 3 & 4.7 & 0.6 & \\
\hline \multicolumn{5}{|l|}{ Gender: } \\
\hline Male & 77 & 13.8 & 8.8 & 0.653 \\
\hline Female & 73 & 13.1 & 10.5 & \\
\hline \multicolumn{5}{|l|}{ Level of education: } \\
\hline No formal schooling & 27 & 11.5 & 10.0 & \\
\hline Grade 1-7 & 14 & 11.6 & 5.4 & \\
\hline Grade 8-12 & 89 & 14.2 & 10.3 & 0.539 \\
\hline Tertiary & 20 & 13.6 & 8.2 & \\
\hline \multicolumn{5}{|l|}{ Marital status: } \\
\hline Never Married & 122 & 14.2 & 10.0 & 0.893 \\
\hline Ever married & 27 & 9.9 & 7.1 & \\
\hline \multicolumn{5}{|l|}{ Smoker: } \\
\hline Yes & 66 & 13.9 & 10.8 & 0.037 \\
\hline No & 84 & 13.0 & 8.6 & \\
\hline \multicolumn{5}{|l|}{ Income categories (Rand): } \\
\hline No income & 73 & 12.6 & 10.2 & \\
\hline $150-2000$ & 32 & 12.7 & 10.0 & \\
\hline $2001-5000$ & 38 & 15.1 & 8.6 & 0.493 \\
\hline Above 5000 & 7 & 16.1 & 9.0 & \\
\hline \multicolumn{5}{|l|}{ Employment status: } \\
\hline Government & 9 & 13.4 & 8.1 & \\
\hline Non-government & 47 & 13.5 & 7.6 & \\
\hline Self-employed & 9 & 18.1 & 15.0 & 0.741 \\
\hline Student & 23 & 14.0 & 8.5 & \\
\hline Unemployed & 60 & 12.5 & 10.8 & \\
\hline Retired & 3 & 13.0 & 9.9 & \\
\hline
\end{tabular}

significant gender variation was found for intensity of binge drinking. This is disturbing, as females who binge drink do so at almost the same rate as their male counterparts. This further corroborates the documented increasing hazardous drinking rate among South African women. ${ }^{7}$ Women are more vulnerable to many adverse consequences of alcohol use than men. Also, women have a greater likelihood of developing organ damage and trauma related to alcohol than men. ${ }^{42}$ With the current ongoing increase in hazardous drinking among women, there is a need for prompt interventions to reduce this adverse behaviour among South African women. Participants aged 36 to 45 years and those who currently smoke had a higher intensity of binge drinking. This finding among current smokers is expected. Nicotine is believed to reduce the intoxicating effects of alcohol, which will likely prompt individuals seeking this effect to drink more. ${ }^{22,41}$ Finally, middle-aged individuals are likely to have more disposable income, which improves their purchasing power and enables them to increase their intensity of binge drinking. 


\section{Strength and limitations}

Although a standardised procedure and questionnaire was utilised in this study, the limitations of this study cannot be ignored. The study was conducted in the health facilities, and utilised a cross-sectional design and self-reporting of lifestyle behaviours. The convenience sampling used in this study might have introduced some bias, thus the rate reported cannot be generalised to the entire BCMM population. Also, it is possible that sampling patients from 18 years of age might have led to under-reporting of the prevalence of binge drinking in the setting as binge drinking has been reported to be higher among adolescents and young adults. However, given the scarcity of information about the frequency and intensity of binge drinking in the Eastern Cape Province of South Africa, the study provides a snapshot of the magnitude of this particular lifestyle behaviour, which is a public health concern in South Africa. Anecdotal evidence has linked high binge drinking with morbidity and mortality in South Africa, including the Eastern Cape. The relatively large sample size of the study gave credence to the findings of this study. In addition, this study provided useful epidemiological data on binge drinking, the findings of which could assist district health managers in crafting effective interventions at the primary health care level across the district to help individuals reduce their level of alcohol consumption to the barest minimum for better healthy living.

\section{Conclusion}

There is an alarmingly high prevalence of binge drinking among the study participants, and those who binge drink tend to do so frequently and at a high intensity. Also, increasing harmful alcohol use was found among the women. There is a need for multilevel interventions to target high-risk drinkers and to create awareness in the general population on the problems associated with hazardous drinking. Finally, primary health care practitioners and district health managers should prioritise awareness creation, screening and implementation of prevention strategies for harmful alcohol use, particularly among young adults.

Acknowledgements - The authors are grateful to the National Research Foundation and the Health and Welfare Sector Education and Training Authority, South Africa for funding the study. They also acknowledge all the patients who took the time to participate in this study.

Conflicts of interest - The authors declare that they have no conflicts of interest.

\section{ORCID}

Oladele Vincent Adeniyi (D) http://orcid.org/0000-0003-02166701

\section{References}

1. National Institute on Alcohol Abuse and Alcoholism. Alcohol facts and statistics. Overview of alcohol consumption, 2014 [cited 2016 July 4]:11-6. Available from: https://www.niaaa.nih.gov/alcoholhealth/overview-alcohol-consumption/alcohol-facts-and-statistics.

2. World Health Organization. Alcohol. Media Centre. 2015. [cited 2016 June 26]. Available from: https://www.who.int/mediacentre/ factsheets/fs349/en/.

3. World Health Organization. The top ten leading causes of deaths in the world, 2000 and 2012. WHO factsheets. 2014. [cited 2016 January 12]. Available at: https://www.who.int/mediacentre/factsheets/ fs310/en/.

4. Herrick C, Parnell S. Alcohol, poverty and the South African City. S Afr Geograph J. 2014;96(1): 1-14.
5. Seggie J. Alcohol and South Africa's youth. S Afr Med J. 2012;102:587 https://doi.org/10.7196/SAMJ.6003

6. Evans M. Alcohol and drinking: a re-think of the way we drink. 2015 [cite 2017 June 27]. Available from: https://www.reframehealthlab. com/a-re-think-of-the-way-we-drink/.

7. Morojele NK, Ramsoomar L. Addressing adolescent alcohol use in South Africa. S Afr Med J. 2016;106:551-3. https://doi.org/10.7196/ SAMJ.2016.v106i6.10944

8. Ramsoomar L, Morojele NK. Trends in alcohol prevalence, age of initiation and association with alcohol-related harm among South African youth: Implications for policy current alcohol policy in South Africa. South Afr Med J. 2012;102: 609-12. https://doi.org/10.7196/ SAMJ.5766

9. Center for Disease Prevention and Control. Binge drinking-United States, 2011. Morb Mortal Weekly Rep. 2013;62: 77-80.

10. Centre for Disease Control and Prevention. Health people 2010 final review. Washington DC: US Government printing office; 2010.

11. World Health Organization. International guide for monitoring alcohol consumption and related harm. Geneva: World Health Organization; 2000.

12. Centre for Disease Control and Prevention. Vital signs: binge drinking among women and high school girls - United States. Morb Morta Weekly Rep 2011;11(62):9-13.

13. Wen XJ, Kanny D, Thompson WW, et al. Binge drinking intensity and health-related quality of life among US adult binge drinkers. Prev Chronic Dis. 2012, 9: e86.

14. Setlalentoa BMP, Pisa TP, Thekisho GN, et al. The social aspects of alcohol misuse/abuse in South Africa. S Afr J Clin Nutr. 2010;23(3 (Supplment 1):11-5. https://doi.org/10.1080/16070658.2010.11734296

15. Owolabi EO, Goon DT, Adeniyi OV, et al. Social epidemiology of hypertension in Buffalo City Metropolitan Municipality (BCMM): cross sectional study of determinants of prevalence, awareness, treatment and control among South Africa adults. BMJ Open. 2017, 7(6):eo14349.

16. Statistics South Africa. South African Statistics. South Africa 2011;1190. Available from: http://www.statssa.gov.za/publications/ SAStatistics/SAStatistics2011.pdf.

17. World Health Organization. Distribution: general steps: a framework for surveillance: The WHO STEPwise approach to surveillance of noncommunicable diseases (STEPS), Geneva. 2003. [cited 2017 April 10]. Available from: www.who.int/...surveillance/.../steps_framework_dec03.pdf.

18. Peltzer K, Davids A, Njuho P. Alcohol use and problem drinking in South Africa: findings from a national population-based survey. Afr J Psych. 2011;14:30-7.

19. Kanny D, Liu Y, Brewer RD, et al. Vital signs: Binge drinking prevalence, frequency, and intensity among adults - United States, 2010. Morb Mortal Weekly Rep. 2013;61: 14-9.

20. Hingson RW, Zha W, White AM. Drinking beyond the binge threshold: Predictors, consequences, and changes in the U.S. Am J Prev Med. 2017;52: 717-27. https://doi.org/10.1016/j.amepre.2017.02.014

21. Reddy SP, James S, Sewpaul R. Umthente Uhlaba Usamla. The South African Youth Survey 2008. Cape Town: Medical research Council. 2010.

22. Johnston RD, Horowitz $M$, Maddox AF, et al. Cigarette smoking and rate of gastric emptying: effect on alcohol absorption. Bri Med J. 1991;302: 20-23. https://doi.org/10.1136/bmj.302.6767.20

23. Erol A, Karpyak VM. Sex and gender-related differences in alcohol use and its consequences: Contemporary knowledge and future research considerations. Drug Alcohol Depend. 2015;1: 1-13. https://doi. org/10.1016/j.drugalcdep.2015.08.023

24. Bratberg GT, Wilsnack SC, Wilsnack R, et al. Gender differences and gender convergence in alcohol use over the past three decades (1984-2008), the HUNT study, Norway. BMC Public Health. 2016;16: 723-9. https://doi.org/10.1186/s12889-016-3384-3

25. Rahav G, Wilsnack R, Bloomfield, K, et al. The influence of societal level factors on men's and women's alcohol consumption and alcohol problems. Alcohol. 2006;41: i47-55. https://doi.org/10.1093/alcalc/ agl075

26. Kerr-Corrêa F, Tucci AM, Hegedus AM, et al. Drinking patterns between men and women in two distinct Brazilian communities. Rev Bras Psiquiatr. 2008;30:235-42. https://doi.org/10.1590/S151644462008000300010 
27. U.S. Preventive Service Task Force. Alcohol misuse screening and behavioural counselling interventionsin primarycare.2013. [cited 2017 June 23]. Available from: https://www.uspreventiveservicestaskforce. org/Page/Document/UpdateSummaryFinal/alcohol-misusescreening-and-behavioral-counseling-interventions-in-primary-care.

28. Keyes M, Hasin DS. Socio-economic status and problem alcohol use: the positive relationship between income and the DSM-IV alcohol abuse diagnosis. Addiction 2008;103: 1-15.

29. Cerdá M, Diez-Roux AV, Tchetgen ET, et al. The relationship between neighbourhood poverty and alcohol use: estimation by marginal structural models. Epidemiol. 2010;21: 482-89. https://doi. org/10.1097/EDE.0b013e3181e13539

30. Matheson $\mathrm{Fl}$, White $\mathrm{HL}$, Moineddin $\mathrm{R}$, et al. Drinking in context: the influence of gender and neighbourhood deprivation on alcohol consumption. J Epidemiol Comm Health. 2011;66:e4.

31. Mulia N, Karriker-Jaffe KJ. Interactive influences of neighbourhood and individual socioeconomic status on alcohol consumption and problems. Alcohol. 2012;47:178-86. https://doi.org/10.1093/alcalc/ agr168

32. Public Health England. Alcohol treatment in England 2013-14. London: Public Health England; 2014.

33. Mossakowski KN. Is the duration of poverty and unemployment a risk factor for heavy drinking? Soc Sci Med. 2008;67:947-55. https://doi. org/10.1016/j.socscimed.2008.05.019

34. Mulia N, Schmidt L, Bond J, et al. Stress, social support and problem drinking among women in poverty. Addiction. 2008;103: 1283-93. https://doi.org/10.1111/add.2008.103.issue-8

35. National Institute of Alcohol Abuse and Alcoholism. Alcohol and nutrition. 2000. [cited 2017 June 10]. Available from: https://pubs. niaaa.nih.gov/publications/aa22.htm.
36. Owolabi EO, Goon DT, Adeniyi OV. Prevalence and factors associated with smoking among adults attending selected healthcare facilities in Buffalo City Metropolitan Municipality, South Africa. S Afr Fam Pract. 2017;1(1): 1-7.

37. Jiang $\mathrm{N}$, Lee $\mathrm{YO}$, Ling PM. Association between tobacco and alcohol use among young adult bar patrons: a cross-sectional study in three cities. BMC Public Health. 2014;14:500-9. https://doi. org/10.1186/1471-2458-14-500

38. Karami-Matin BM, Barati SN, Hossieni D, et al. Sensation seeking is related to cigarette smoking and alcohol drinking among college students? Int J Trop Med. 2016;11: 28-32.

39. Room R. Smoking and drinking as complementary behaviours. Biomed Pharmacother. 2004;58:111-5. https://doi.org/10.1016/j. biopha.2003.12.003

40. Lê AD, Corrigall WA, Harding JWS, et al. Involvement of nicotinic receptors in alcohol self-administration. Alcoholism: Clin Experimen Res. 2010, 24:155-63.

41. Chen WJA, Parnell SE, West JR. Nicotine decreases blood alcohol concentration in neonatal rats. Alcoholism:Clin Experi Res. 2001, 25: 1072-7. https://doi.org/10.1111/acer.2001.25.issue-7

42. National Institute of Alcohol Abuse and Alcoholism. Are women more vulnerable to alcohol's effects? 1991 [cited 2017 July 5]; 46:1. Available from: https://pubs.niaaa.nih.gov/publications/aa46.htm.

Received: 07-07-2017 Accepted: 17-09-2017 